\title{
OSMOTIC ENERGY, A LITTLE-KNOWN RENEWABLE ENERGY SOURCE
}

\author{
E. ANDRADE ${ }^{1}$, J. HERNÁNDEZ ${ }^{1} \&$ C. ARREDONDO ${ }^{2}$ \\ ${ }^{1}$ LIFAE, Facultad de Ingeniería, Universidad Distrital Francisco José de Caldas, Bogotá, Colombia. \\ ${ }^{2}$ Facultad de Ingeniería, Ingeniería en Energía, Universidad de Medellín, Colombia.
}

\begin{abstract}
When the rivers lead into the sea, it merges two water bodies with different salinity level, releasing a large amount of energy when the solutions equilibrate its concentrations; this phenomenon is known as osmosis. With the purpose to use this energy to transform it into electricity, it has been developed a device with a semi-permeable membrane, when is placed between the solutions with different saline concentration, allows to equalize the concentration at a constant pressure or volume. The membrane behavior on the device is similar to the behavior of the living being cells membrane, that's the reason to call the device as a membrane module. Using a membrane module array is possible to get brackish water, with a pressure corresponding to the osmotic pressure that represents hydraulic energy that could be transformed into electricity by well-known means. This work presents a conceptual methodology for preliminary design of an osmotic power plant, which could be a theoretical reference for different alternatives to generate electricity in the places where it's possible to implement it, as the way to dimension and design the system, including concepts and parameters related to conventional, energy-production processes, allowing to know different methods for energy production that someday could be competitive with the traditional energy generation.

Keywords: electricity generation, osmotic energy.
\end{abstract}

\section{INTRODUCTION}

The energy from osmosis is popularly known as "blue energy" or pressure retarded osmosis (PRO) [1] and must not be confused with reverse osmosis (RO) [2]. From the different sources to generate electricity, this paper makes a brief description about osmotic energy, an unknown alternative energy source (studied since 70 s decade). It uses semi-permeable membrane and takes advantage from the osmotic potential between two water bodies with different salt concentration, as in the case of river mouths into the sea, according to the validating patent from Finley and Pscheidt [3]. Technological advances of this kind of application could become an adequate alternative for electricity generation thanks to being environmentally friendly. It is important to study and show its possibilities for energy development purposes.

\section{SYSTEM CHARACTERISTICS}

Some characteristics of the osmotic energy generation are:

1. It is a renewable energy source, depending on an almost inexhaustible resource.

2. It is hydro-generated, due to turbine-generator system used.

3. It is a marine energy generator, due to its seawater usage.

4. It is a clean energy source, does not produce $\mathrm{CO}_{2}$ emissions.

This paper is part of the Proceedings of the $6^{\text {th }}$ International Conference on Energy and Sustainability (ESUS 2015)

www.witconferences.com
} 
5. It can be continuously used.

6. It is reliable. The water operation fluxes are constant and with regular pressures, reflected in stable outflow.

7. It is safe. It does not use or present risks as in the case of a nuclear central energy generation. It could be powered off similar to a hydroelectric central.

8. Its modular design allows an easy (preventive and corrective) maintenance due to the membranes used.

9. The system is upgradable, thanks to the improvements in some components such as membranes and pre-treating systems.

\section{R.S. NORMAN SCHEMATIC DIAGRAM}

The osmotic energy generation system is presented in Fig. 1 developed by Norman [4]. The water of the river permeates through the membrane going to the sea water, increasing the pressure at constant volume, the water in the chamber rises to a certain height gaining potential energy, which is then released as a head of water to a turbine connected to a generator. The pump shown in the scheme uses the mechanical energy to pump the seawater allowing the continuous working of the system. Unused freshwater goes to the sea directly.

\section{HEIGHT REACHED BY THE OSMOTIC PRESSURE}

On Fig. 1, height $h$ fixed, corresponds to the reached height by the salt water due to osmotic pressure. To know that height, it is possible to equalize it with hydrostatic pressure [5], as described by eqn (1):

$$
H p=A p+\rho \cdot g \cdot h
$$

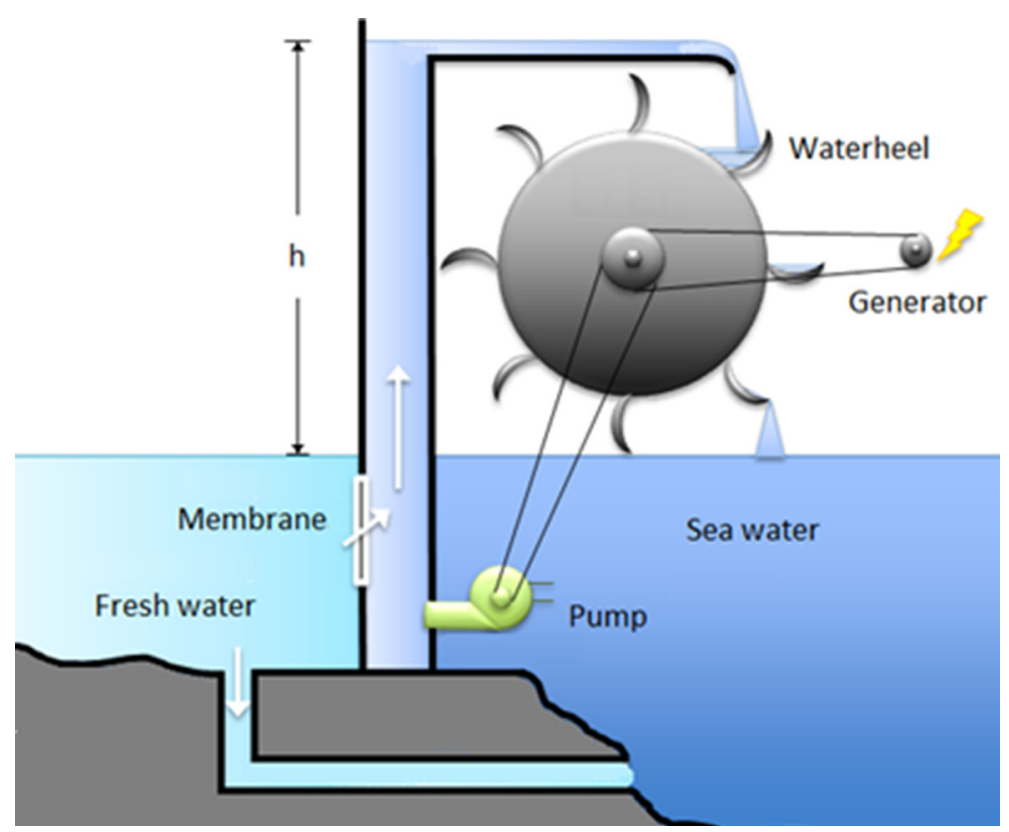

Figure 1: Schematic diagram showing the advantages of osmotic pressure to generate hydro and then electrical energy [4]. 
Where:

: Hydrostatic pressure in $[\mathrm{Pa}]$

: Atmospheric pressure $[100 \mathrm{kPa}]$

: Water density $\left[1,000 \mathrm{~kg} / \mathrm{m}^{3}\right]$

: Gravity $\left[9,81 \mathrm{~m} / \mathrm{s}^{2}\right]$

: Height [m]

The osmotic pressure, according to Loeb and Norman [6], varies from 0.6 to $1.1 \mathrm{psi}$ for each $100 \mathrm{ppm}$ of the total of dissolved solids. Then, taking as example sea water (as the one of the Pacific ocean) with 33,600 ppm of dissolved solids, it will be obtained around $336 \mathrm{psi}$, which are equal to $2.316 .639,06 \mathrm{~Pa}$. Equalizing the osmotic and hydrostatic pressure, the height is determined by using eqns (2) and (3), as follows:

$$
\begin{aligned}
& 2316639,06 P a=100000 P a+\left(1000 \frac{\mathrm{kg}}{\mathrm{m}^{3}}\right)\left(9,81 \frac{\mathrm{m}}{\mathrm{s}^{2}}\right) \cdot h \\
& h=\frac{2216639,06 \mathrm{~Pa}}{\left(9810 \frac{\mathrm{kg}}{\mathrm{m}^{2} \cdot \mathrm{s}^{2}}\right)}=\frac{2216639,06 \frac{\mathrm{kg}}{\mathrm{m} \cdot \mathrm{s}^{2}}}{\left(9810 \frac{\mathrm{kg}}{\mathrm{m}^{2} \cdot \mathrm{s}^{2}}\right)}=225,96 \mathrm{~m}
\end{aligned}
$$

One of the determining factors to implement osmotic energy involves the use of a pressure exchanger that takes the advantage of half of the output flow to pump the water sea, maximizing the membrane and system performance, but representing theoretically, a head of $120 \mathrm{~m}$. The solids dissolved in freshwater are not taken into account in this calculation, because they are insignificant.

\section{PROTOTYPE PLANT IMPLEMENTED IN TOFTE, NORWAY}

It is known that the company Statkraft has implemented a test plant in Tofte, Hurum in Norway in 2009. It has been designed to generate around $4 \mathrm{~kW}$ [7]. It operates by simulating a fall, where instead of transforming the osmotic power into potential energy; unlike the R.S. Norman scheme; sends the pressure obtained from the membranes to the turbine, with a flow rate of around 4 liters per second. A modular diagram of the built plant in Tofte is displayed in Fig. 2 [8].

To capture the river water, it seeks to take the advantage of the slope and the fact that it is flowing to the sea, and later, it is submitted to a pre-treating where dirtiness and other elements that could obstruct the membrane are removed, then it is deposited in a pressurized tank, sea water is pumped, and when it is leveled to sea-level energy is saved. Membranes are filled with two portions of freshwater by one portion of seawater, there, the osmosis process will occur and freshwater will permeate the saltwater compartment, increasing the pressure that goes to the turbine. It is important to keep regulate the membranes' pressure not to exceed the osmotic pressure and for not interrupting or creating inverse osmosis, and to optimize the membrane's performance. That's the reason to pressurize the seawater at half of the osmotic pressure before entering to the membrane. After leaving the turbine, the resulting water is brackish and sent to the sea. On the other hand, freshwater entering the membranes and not permeating the side of salt water is evacuated. Figure 3 shows the different parts of the system, and Fig. 4 shows the schematic design to give a better system interaction understanding. 


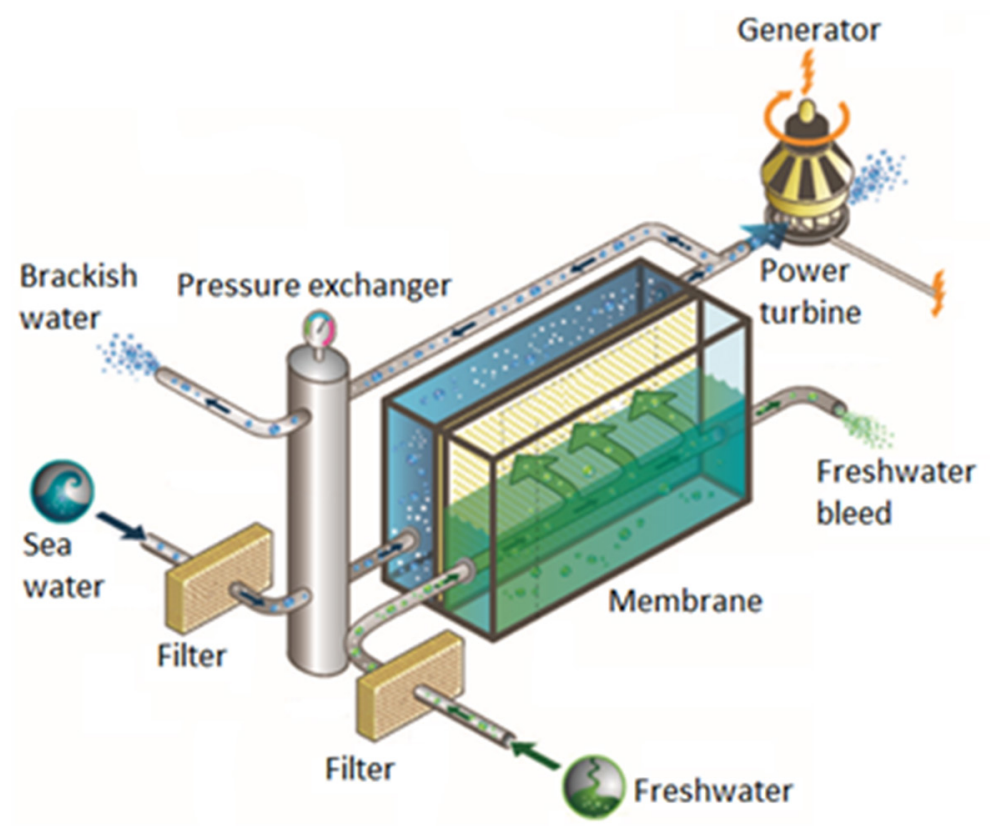

Figure 2: Modular diagram of the built plant in Tofte [9].

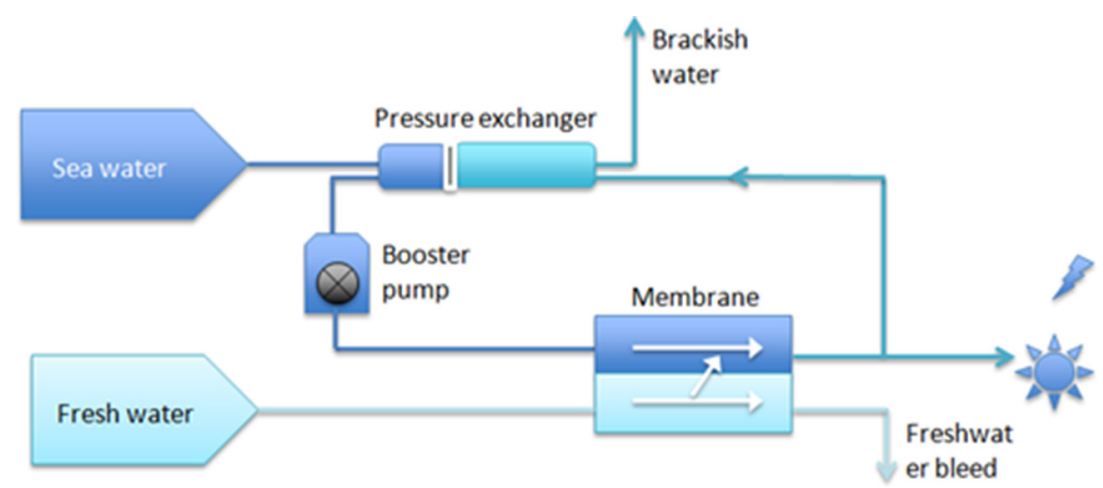

Figure 3: System parts and connection [9].

The elements on which its performance and efficiency could be improved though investigation is the membranes pressure exchanger, salt water and pre-treatment system. The performance of water pumps, pipes, and valves depends more on a good and reliable design.

Fig. 5 depicts a pump booster type which compensates the hydraulic-hydraulic losses occurred in the pressure exchanger, optimizing the system's performance.

\section{ANALYSIS OF SYSTEM FLUIDS}

The membrane's output takes around the half of the pressure to pump seawater and that two parts of freshwater by one part of saltwater, as depicted in the diagram of Fig. 5.

where:

Sw: Salt water 


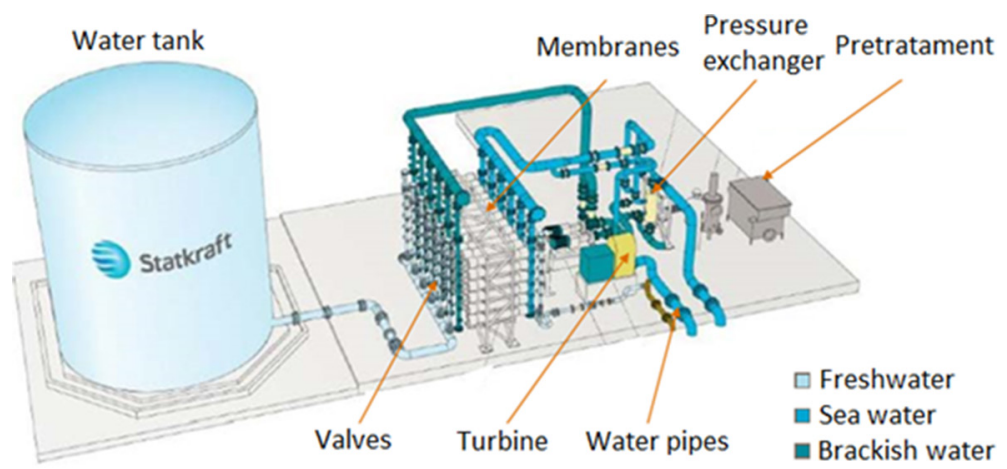

Figure 4: Schematic design of prototype plant built in Tofte [1].

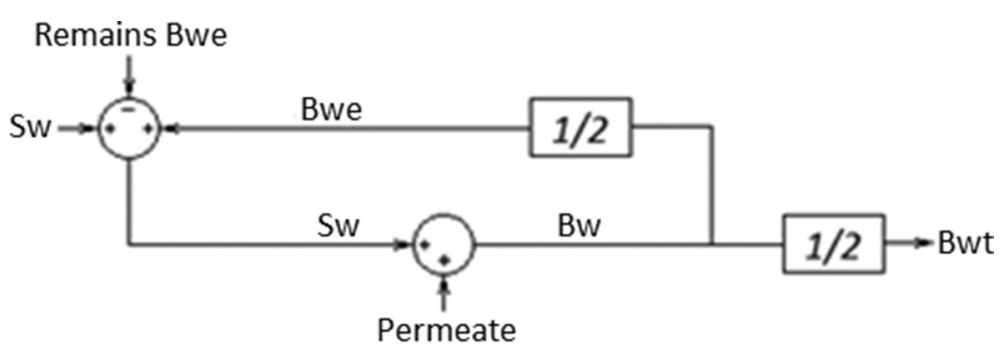

Figure 5: Block diagram of system`s fluxes (self-elaboration).

Bw: Brackish water

Bwt: Brackish water in the turbine

Bwe: Brackish water in the pressure exchanger

Remains Bwe: Brackish water remains of the exchanger

Permeate: Freshwater flux permeating salt water compartment.

Such that, results the eqn (4) for the systems fluxes:

$$
S w-\text { Remains } B w_{e}+B w_{e}+\text { Permeate }=B w
$$

And given the conditions: $B w_{e}=\frac{B w}{2}$, and Remains $B w_{e}=\frac{B w}{2}=B w_{e}$, results the eqn (5):

$$
S w+\text { Permeate }=B w
$$

However, brackish water going to the turbine corresponds to the half of brackish water coming out from the membrane, $\mathrm{Bw}$ _t $=\mathrm{Bw} / 2$, so finally is obtained the brackish water sent to the turbine as described by eqn (6):

$$
\frac{(S w+\text { Permeate })}{2}=B w_{t}
$$

It means that resulting brackish water corresponds to the half of salt water incoming plus the freshwater permeating the compartment of salt water of the membrane. Salt water is pumped with the osmotic pressure that helps using the pressure exchanger; and at the 


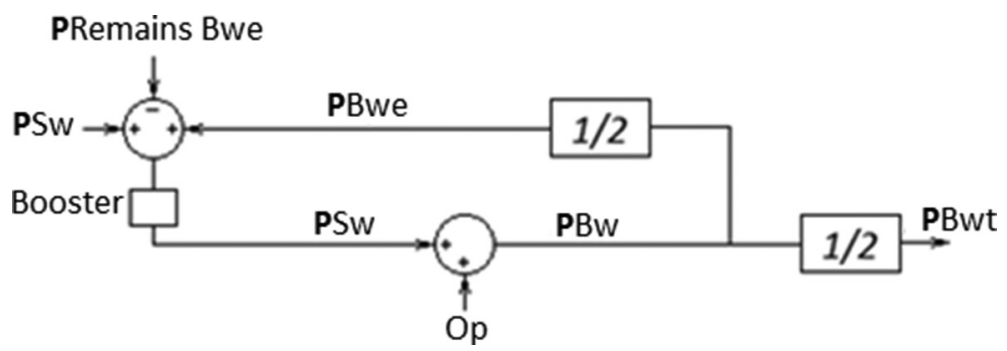

Figure 6: Block diagram for the pressures of the system (self-elaboration).

same time; the exchanger has small loses supplied by a booster pump (previously mentioned).

\section{SYSTEM PRESSURES ANALYSIS}

Figure 6 shows the system's pressure.

where, similarly have:

PSw: Salt water pressure

PBw: Brackish water pressure

PBwt: Brackish water pressure on the turbine

PBwe: Brackish water pressure on the pressure exchanger

PRemains Bwe: Brackish water pressure remaining on the exchanger

Op: Osmotic pressure

Resulting in eqn (7) as follows:

$$
\text { Booster }\left(P S w-\text { PRemains } B w_{e}+P B w_{e}\right)+O p=P B w
$$
And with given conditions: $P B w_{e}=\frac{P B w}{2}$, and PRemanis $B w_{e}=\frac{P B w}{2}=P B w_{e}$, results
eqn (8):

$$
\text { Booster } * P B w+O p=P B w
$$

However, the pressure on the remaining brackish water that flows to the turbine corresponds to the half of pressure exiting from the membrane $B w_{t}=\frac{B w}{2}$, making possible to obtain the pressure on the remaining brackish water of the systems by means of eqn (9):

$$
\frac{\left(\text { Booster }^{*} P S w+O p\right)}{2}=P B w_{t}
$$

Booster pump will be enough to break the pressure equilibrium on the system, permitting the income of seawater to the membrane (which gives almost negligible pressure). Therefore, the booster factor is negligible. According to that, the brackish water directed to the turbine is obtained, as described by eqn (10):

$$
\frac{O p}{2} \approx P Q w_{t}
$$

From the nature of the system's fluids, fresh water, and seawater, both considered uncompressible, there's no pressure increase in the membrane as it occurs if the fluids were gases. 


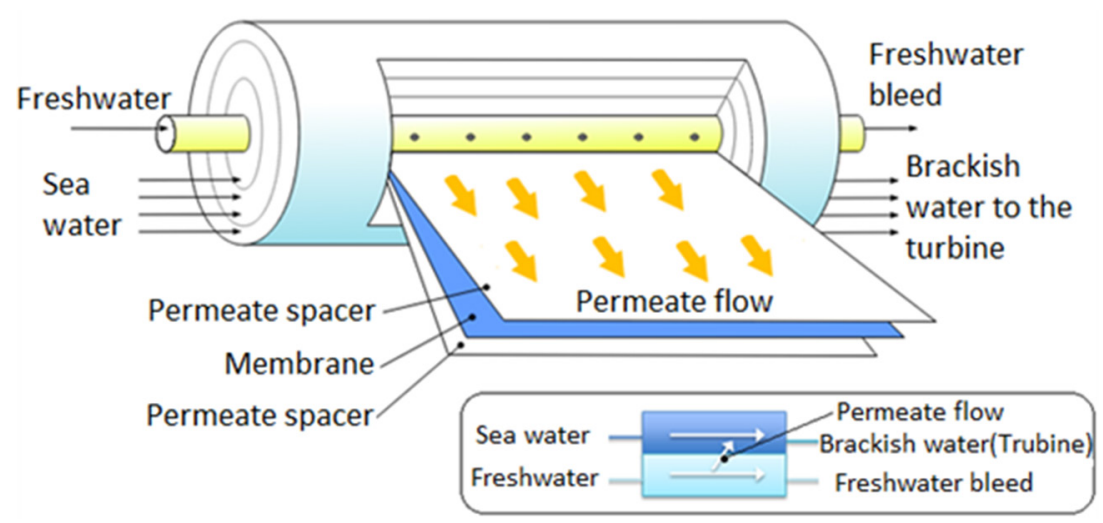

Figure 7: Membrane fluxes description. Based on: Spiral wound membrane module available for free under Creative Commons License [8].

The absence of the pressure increasing will be reflected by an immediate exit pressure entering, which means, equivalent to the osmotic pressure plus the difference in pressure caused by the booster pump.

\section{MEMBRANE'S FLUXES DESCRIPTION}

Figure 7 shows how freshwater enters in the center of the roll where it is distributed through holes at one side of the compartment and salt water enters the other side of the compartment. The outputs are the remaining freshwater that does not permeate salt water and brackish water, and goes to the turbine.

The membrane fluids are pressurized, in that way, the membrane must be designed to hold up the pressures and operation temperature. The modules are shunt connected to the membrane, adding up the individual areas to shape the total membrane area.

\section{MEMBRANE'S EFFICIENCY ANALYSIS}

The efficiency of membranes is a function of the total amount of obtained power per membranes area. Experimentally, according to laboratory analysis from Lee et al. [10]and Achilli [11], it was found that the achieved efficiency with tri-acetate cellulose sheet is of $5 \mathrm{~W} / \mathrm{m}^{2}$; it was also found that power efficiency losses were caused by the polarization of internal concentration. With a lower resistivity module membrane (thinner and with the same structural resistance), it could achieve an efficiency of around $30 \mathrm{~W} / \mathrm{m}^{2}$. Tofte prototype tower uses a membrane with $1 \mathrm{~W} / \mathrm{m}^{2}$ of efficiency. Therefore, one of the main objectives of the prototype plant is to improve the efficiency of the membrane up to $5 \mathrm{~W} / \mathrm{m}^{2}$, making the osmotic system a competitive energy source. So the conditions for efficiencies are contemplated from 1 to 5 $\mathrm{W} / \mathrm{m}^{2}$ (eqn 11 ):

$$
\frac{\text { Required power }}{\text { Efficiency of the membrane }}=\text { Area of the membrane }
$$

Where:

Efficiency of the membrane: efficiency varying from 1 to $5 \mathrm{~W} / \mathrm{m}^{2}$ 
Table 1: Membrane efficiencies.

\begin{tabular}{lrr}
\hline Efficiency & $\mathrm{m}^{2}$ & \#Module \\
$1 \mathrm{~W} / \mathrm{m}^{2}$ & 150,0 & 5,36 \\
$2 \mathrm{~W} / \mathrm{m}^{2}$ & 75,0 & 2,68 \\
$3 \mathrm{~W} / \mathrm{m}^{2}$ & 50,0 & 1,79 \\
$4 \mathrm{~W} / \mathrm{m}^{2}$ & 37,5 & 1,34 \\
$5 \mathrm{~W} / \mathrm{m}^{2}$ & 30,0 & 1,07 \\
\hline
\end{tabular}

Required power: Power in kW

Area of the membrane: Area in $\mathrm{m}^{2}$

On the other hand, taking into account that each module of the membrane has around of 28 $\mathrm{m}^{2}$, the total amount of necessary modules using the eqn (12) is calculated:

$$
\frac{\text { Required membrane area }}{28 m^{2}}=\text { Total ammount of necessary modules } \text {. }
$$

From equations (11) and (12), for different efficiencies values were obtained. Table 1 indicates the area and the total amount of necessary modules for each efficiency value. Those calculations were carried out taking into account a generation power of $150 \mathrm{~W}$.

From the results of Table 1, it is found that a tendency to decrease the area of the membrane when efficiency improves.

\section{ECONOMIC ANALYSIS OF THE SYSTEM AS FUNCTION OF THE EFFICIENCY OF THE MEMBRANE}

According to gathered information by Achili and Childress [1] to evaluate the current economic pre-feasibility of the osmotic system for energy generation, it is necessary to multiply the power density of the membrane by the kilowatt-hour price, its result gives the income for each square meter per year (eqn 13).

$$
\frac{\text { Incomes }}{\text { Area of the embrane } * \text { year }}=\text { Energy price } * \text { Power density }
$$

A membrane for this use must generate $5 \mathrm{~W} / \mathrm{m}^{2}$ net to produce energy at a competitive cost compared to conventional sources, or $3 \mathrm{~W} / \mathrm{m}^{2}$ to be comparable with other renewables sources. The power density of $3 \mathrm{~W} / \mathrm{m}^{2}$ means a significant increase to the performance of 0.1 $\mathrm{W} / \mathrm{m}^{2}$ from some years ago. This development shows that its actual implementation at midsize is close. For the current analysis, the incomes per square meter per year, for the plant were determined with the following conditions: power density of $3 \mathrm{~W} / \mathrm{m}^{2}$, and average $\mathrm{kWh}$ cost (in Colombia) of $400 \mathrm{COP} / \mathrm{kWh}(1 \mathrm{U} \$ \approx 2600 \mathrm{COP})$, as depicted in eqns (14)-(16), as follows.

$$
\begin{gathered}
\frac{\text { Incomes }}{\text { Area of the embrane } * \text { year }}=\frac{400 C O P}{K W h} * \frac{3 W}{m^{2}} \\
\frac{\text { Incomes }}{m^{2} \cdot \text { year }}=\frac{1200 C O P}{1000 W h} * \frac{W}{m^{2}}
\end{gathered}
$$




$$
\frac{\text { Incomes }}{m^{2} \cdot \text { year }}=1.2 \frac{C O P}{m^{2} \cdot h}
$$

Allowing to obtain the incomes per square meter per hour of $1.2 \mathrm{COP}$, and then is calculated for 1 year by using the eqns (17) and (18):

$$
\begin{aligned}
& \frac{\text { Incomes }}{m^{2} \cdot \text { year }}=\frac{C O P}{m^{2} \cdot h} * \frac{8760 h}{y e a r} \\
& \frac{\text { Incomes }}{m^{2} \cdot \text { year }}=10512 \frac{\text { COP }}{m^{2} \cdot \text { year }}
\end{aligned}
$$

Therefore, incomes per square meter per year are $10.512 \mathrm{COP}$, representing that for an efficiency of $5 \mathrm{~W} / \mathrm{m}^{2}$ membrane is possible to recover $66 \%$ more than the recovery with the $3 \mathrm{~W} / \mathrm{m}^{2}$ membrane. Analysis of incomes as a function of $\mathrm{kWh}$ cost for 1, 5, 10 and 15 years showed that the membrane's lifetime must be taken into account, because it allows to amortize the initial investment as could be seen in Fig. 8.

The carried out analysis takes into account the kWh cost varying from 150 to 500 COP, which may occurs in the time intervals.

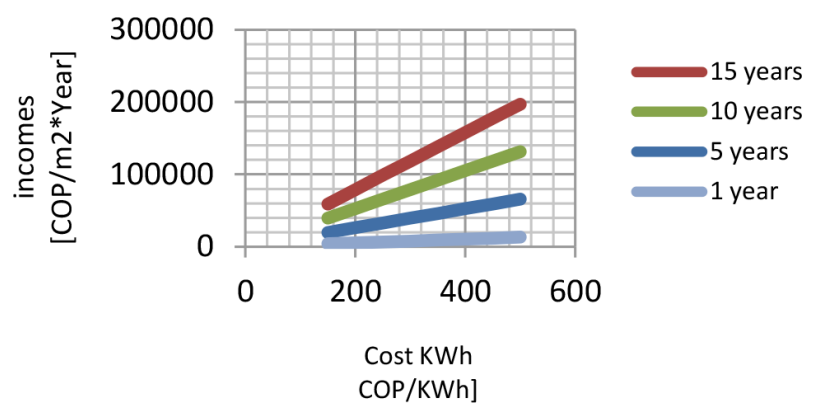

Figure 8: Incomes as a function of kWh cost for an efficiency of $3 \mathrm{~W} / \mathrm{m}^{2}$ membrane.

Table 2: Salinity variation in the world [12].

\begin{tabular}{ll}
\hline Sea or Ocean & Approximate salinity $(\mathrm{ppm})$ \\
\hline Baltic Sea & 7,000 \\
Black Sea & 13,000 \\
Adriatic Sea & 25,000 \\
Mediterranean Sea & 31,500 \\
Pacific Ocean & 33,600 \\
Indian Ocean & 33,800 \\
Caribbean Sea & 38,600 \\
Atlantic Ocean & 39,400 \\
Arabian Gulf & 43,000 \\
Red Sea & 43,000 \\
\hline
\end{tabular}


Table 3: Water types according to its salinity (TDS) [12].

\begin{tabular}{lc}
\hline Water type & Salinity (ppm to TDS) \\
\hline Ultra-pure & 0,03 \\
Pure & 0,3 \\
Deionized & 3 \\
Sweet & $<1,000$ \\
Brackish & $1,000-10,000$ \\
Saline & $10,000-30,000$ \\
Marine & $30,000-50,000$ \\
Brine & $>50,000$ \\
\hline
\end{tabular}

\section{NATURAL RESOURCES REQUIRED FOR THE USING OF OSMOSIS FOR ENERGY GENERATION}

River mouths into the sea are the optimal places to install osmotic energy generation power plants. It does not need any other natural resource. This kind of energy source does not use fossil fuels, does not depend on the sun or wind. Water is returned to the sea with no pollutants, and is a renewable source. Osmosis occurs when the concentration varies, and resulting osmotic pressure depends on dissolved solids or salts. To avoid the analysis of compounds and portions of seawater and freshwater, which are not the same in different places of the world, it is given a relation as a function of the dissolved solids in parts per million per water liter, as shown in Table 2.

River water, fresh water, or runoff has no high-salt levels as could be seen in Table 3, but cold have dissolved solids as sludge, debris, or pollutants caused by mankind action, which is reflected in pre-treatment overheads making the Project non-viable. In osmosis processes, it is important to know the water salinity, because it is an important factor to choose the adequate semi-permeable membrane. Table 3 various types of water and the salinity ratio in ppm (parts per million) are given.

\section{TECHNICAL DESIGN, DETAILS FOR PRELIMINARY DESIGN}

A starting point is the required power and available rate flow, and it ends giving technical information to select equipment and appropriate materials. Technical design sequence is presented in Fig. 9.

It is possible that the osmotic design process to be limited due to the scarcity of necessary resources, for example, energy demand that exceeds the available water flow, economical aspects, membrane quality, etc. The relationship between power, water flow and membrane area describes a cyclic behavior as shown in Fig. 10.

The most important factor is the required power, because it allows or not to make the Project available.

\subsection{Required power}

If the required power is not yet determined, it is necessary to know the energy generation capacity. The result must be achieved as a function of rate flow and the membrane area. 


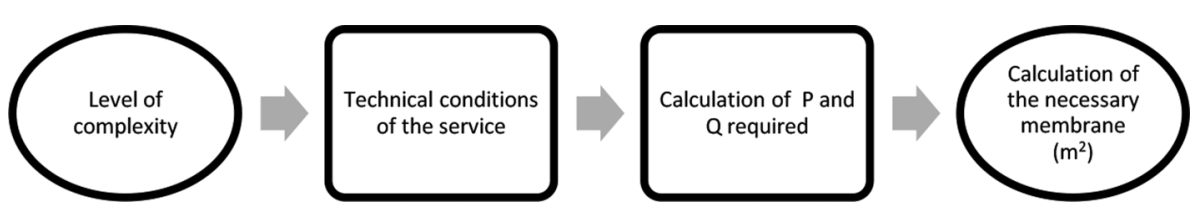

Figure 9: Sequence for compiling the technical design.

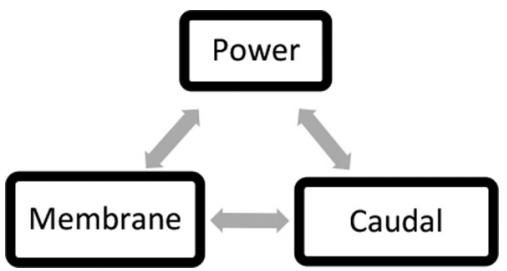

Figure 10: General scheme for technical design.

\subsection{Rate flow required}

Equation (19) allows to calculate the required rate flow.

$$
B w_{t} \frac{P}{\rho^{*} g^{*} h^{*} e}
$$

where:P: Instant power required [W]

$\rho$ : Liquid density $\left[1000 \mathrm{~kg} / \mathrm{m}^{3}\right]$

$\mathrm{g}$ : Gravity $\left[9,81 \mathrm{~m} / \mathrm{s}^{2}\right]$

Bwt: Brackish water rate flow going to the turbine $\left[\mathrm{m}^{3} / \mathrm{s}\right]$

h: Height (artificial jump of $120 \mathrm{~m}$ )

e: Efficiency factor of the plant. It is equal to the product of the performances for the equipment involved in energy production (turbine, generator, and transformer).

\section{CONCLUSIONS}

Osmotic pressure allows to generate electricity from the water flow, which is used in Pelton turbine. This energy generation source could be an adequate and alternative energy source. However, it is necessary to make a deeper study before its high-scale implementation.

The pressure exchanger, which uses half of the output pressure to pump the water to the sea, is one of the key elements in osmotic energy, because it allows to maximize the membrane and system performance.

In the membrane, it is important to regulate the pressure to not surpass the osmotic pressure for not allowing inverse osmosis, and maximizing the membranes performance. That's one of the reasons to pressurize seawater to around the half of the osmotic pressure, before entering to the membrane.

Membrane and pre-treatment system are elements to study, and to improve its efficiency and performance. At higher membrane efficiency, fewer modules are needed. Water pumps, pressure exchanger, pipes, and valves depend more on the design process. 
The design and development of the membrane, as well as its operating lifetime is the key objective that could make technically and economically the osmotic energy generation projects possible.

\section{REFERENCES}

[1] Achilli, A. \& Childress, A.E., Pressure retarded osmosis: from the vision of Sidney Loeb to the first prototype installation - Review. Desalination, 261(3), pp. 205-211, 2010. http://dx.doi.org/10.1016/j.desal.2010.06.017

[2] Kucera, J., Reverse Osmosis: Design, Processes, and Applications for Engineers, Wiley: Golden, Colorado, 2010. http://dx.doi.org/10.1002/9780470882634

[3] Finley, W. \& Pscheidt, E., Patent no ES 2242599 T3. EUROPE, (01/02/2000).

[4] Norman, R.S., Water salination: a source of energy. Science, 186(4161), pp. 350-352, 1974. http://dx.doi.org/10.1126/science.186.4161.350

[5] Serway, R., Física para ciencias e ingeniería, 6ta Edición., Cengage Learning, 2009.

[6] Loeb, S. \& Norman, R., Osmotic power plants. Science, 189, pp. 654-655, 1975. http://dx.doi.org/10.1126/science.189.4203.654

[7] Norway opens world's first osmotic power plant. Online, available at www.reuters.com/ article/2009/11/24/us-norway-osmotic-idUSTRE5AN20Q20091124

[8] Aushulz., Spiral flow membrane module, available at Online https://upload.wikimedia. org/wikipedia/commons/e/eb/Spiral_flow_membrane_module.jpg, 2008

[9] Osmotic power membrane ilustration, available at Online, http://bit.ly/127U0Ia

[10] Lee, K.L., Baker, R.W. \& Lonsdale, H.K., Membrane for power generation by pressure retarded osmosis. Science, $\mathbf{8}$, pp. 141-171, 1981. http://dx.doi.org/10.1016/s0376-7388(00)82088-8

[11] Achilli, A., Power generation with pressure retarded osmosis: an experimental and theoretical investigation. Science, 343, pp. 42-52, 2009. http://dx.doi.org/10.1016/j.memsci.2009.07.006

[12] Montes, G., Water desalination by reverse osmosis. Upcommons, p. 17, 2009. 